\title{
Create school teaching management communication platform
}

\author{
Bin Peng \\ MianYang Normal University, MianYang, China

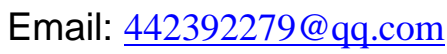

\begin{abstract}
Keywords: Teaching management; Interface; Communication platform
\end{abstract}
\begin{abstract}
: the school teaching management essentially decides the school teaching quality and students' physical and mental development level. This article use engineering technology interface analysis, hoping to find the school teaching management, establish the interface contradiction of school teaching management to improve communication platform, our country school teaching management level, improve the quality of teaching in schools, have a certain significance.
\end{abstract}

\section{Introduction}

The basic purpose of education is to build and develop the individual. Schools as of teaching, the task is to make important pedagogue get personality and quality of the perfect teaching. Cas members, Mr. Shuzi Yang once pointed out: "what is the basic task of the school? First is teaching students how to be a good person; Second is to teach the students how to thinking; Third is to teach students to master necessary, high level of knowledge and ability to apply that knowledge to these three is the dialectical unification, complementary relationship, overall, the basic task of the school talent training. Teaching is school regular work, teaching management in the school management plays very important status. The management of teaching quality success essentially decides the school teaching quality and students' physical and mental development level in teaching management process. And the main parties is school, teacher, student, and between the three starting point and ways of thinking because of different management of teaching, will produce certain differences, this is interface problems. Therefore, to discuss the school teaching management school, teachers and students, the interface between the contradiction to find the solution, interface contradiction to establish the communication platform, the management of teaching in schools teaching goal, to better improve school teaching effect, has the extremely vital significance.

\section{The school teaching management characteristics analysis}

The so-called teaching management is that according to the certain goals, in a management thoughts guidance or influence, through certain teaching organization form and institutions to organize teaching activities of teaching, to regulate the reasonable allocate resources to ensure and use, teaching activities to ensure the healthy and orderly unfolds, the completion of the teaching plan, to ensure the quality of teaching and the teaching purpose has steadily risen realization. The essence of teaching management is to design and keep a kind of good teaching environment, the teachers and students in the process of teaching efficiency to achieve the teaching goal, set to complete the teaching task, students, teachers, school between the three can be harmonious a behavior.

The basic task of teaching management is: research teaching and its management rule, the improvement of teaching management, improve the teaching management level; Establishing stable teaching order, guarantee the normal operation of the teaching work; Research and implementation of teaching reform; Teachers and students to arouse the enthusiasm of teaching and learning.

The school teaching management are summed up and there are three major work, is construction and reform and management. One is to improve the basic construction of teaching solidly. The ba- 
sic construction of teaching means professional disciplines construction, course construction, practice base construction, the style construction, teachers team construction, etc. Two is to actively promote the reform of teaching. Focusing on widen the scope of subject knowledge, teaching content, teaching method, examination method and the link to practice, but also a positive reform school internal educational administration reform. Three is to strictly regulate to implement the teaching management. Teaching management mainly includes teaching quality and teaching order, status and exam, etc management.

Generally speaking, the current school teaching management is characteristic of the school teaching managers and management (service) between the formed a based on education built legal relationship. It is part of the whole education relationship. Judging from the teaching management relations, the characteristics of school management is management diversification of the main body, is the core subject and auxiliary subject combination. The so-called core subject is office affairs. Although the school dean of agency establishment is a department, but its effect is very big. It bears the education policy and implementing countries of the school's teaching target, drafting, work out teaching work plan, check, monitoring the implementation of the plan, to improve teaching facilities and provide the teaching experience, learning conditions, report, coordination and processing, and other important duties; dean 2 it is the teaching management object is the school in addition to people outside of that managers in management activity, the teaching management object is teaching management activity subject to the rights and obligations of the person or thing, not managers, between by managers and the relationship between each other between. In management, under the situation of main determine managing subjects also cannot again be management object, therefore, only in the teaching management relationships outside of except managers itself, can be management object; Three is teaching management relations content is the teaching quality. Will tell from the teaching management, and managers not develop a set of the so-called standard operating procedure, then put teachers and students just like machines, nor to operate for a plan, each person to manage property loss. In the management of the legal relationship managers don't just put teachers and students, people hold, but more important is to put their thoughts and consciousness rein to improve the teaching quality, unified to come up.

\section{The school teaching management interface and interface management connotation}

\section{1 school teaching management interface definitions}

Interface refers to two or more than two between objects interface. Interface term originated in engineering technology, its refers to the related areas, entity, material or stage by the formation of the common boundary between the surface. Along with the interface management and ideas are many, interface between ideas being applied to management activities, used to describe the functional departments rooms, between people and things, processes, between the flow in the connection between the relationship. And the school teaching management interface is to point to in schools teaching management activities, the teaching management's main parties schools, teachers and students relations between each other. The existence of school teaching management interface and, on the other hand, can make the main participants in the school teaching management school, the teacher and student exchanges and communication, in order to achieve the purpose of school teaching management; On the other hand, it is precisely because the interface and allows for the existence of schools, teachers and students of the communication between exist disorder, which school 
teaching management interface contradictions. We think, the school teaching management interface contradictions refers to the main parties teaching management school, the teacher and student, because its treat teaching ideas, their attitude, their respective duties, and the different aspects in the communication mechanism imperfect, resulting from the three aspects of communication between the direction of inconsistent, such problems.

\section{2 school teaching management interface definition connotation}

As you can see, the existence of school teaching management interface to the school, both to the management of teaching effect, bring about a positive impact in the school teaching management to the fact that have brought some negative influence effect, reduce the system efficiency. In order to maintain the normal school teaching management, high efficiency, maintains the school teaching management system and internal and external harmony atmosphere, need school teaching management interface to intervene, to solve the contradiction, the process school interface is interface management.

\subsection{The characteristics of school interface management}

The school teaching management interface has the following features:

\subsection{1 the school teaching management interface exist objectivity}

Marxism believes that the connection is widespread. There are all the other things with external had some connection, the school teaching management system of the connection between the various parties is objective existence, it is precisely because the objective existence, makes contact between these parties separated interface is objective existence.

\subsection{2 the school teaching the permeability of the management interface}

Interface can be separated by different parties, this also means that interface with different parties linked functions. In the school teaching management this system, interface doesn't exist to strict separated by different parties. In the school teaching management face the dominant or recessive gap between the parties that different to mutual infiltration and exchange.

\subsection{3 the school teaching management interface incredibly dynamic}

The subject of school teaching exchange relationship between the changes will inevitably affect inter-subjectivity contact status, i.e., influence interface characters. Therefore, the interface is with school teaching management of various parties the inherent characteristics of and behavior changes.

\subsection{The interface of teaching management conflict analysis}

Because the school teaching management is relatively complex, therefore, in school teaching implementation of process, often encounter some problems, which school teaching can't completely according to established goals progress continues, could not realize the teaching the desired effect. Although in the school teaching problems, but if more school teaching interface management from the perspective of school teaching, the existing problems in the implementation of, all boils down to 
the school teaching management in the main participants in the schools, teachers and students of the interface between contradiction. The interface between the contradictions among them are mainly embodied in the teaching effect, teaching means, teaching methods, teaching implementation evaluation, etc. It is these interface contradictions exist, the direct impact on the effect of school management, affects the school teaching effect. Therefore, we need to find some teaching management school teaching communication platform, solve the existing in the management interface contradiction, guarantees the school teaching management work efficient development.

\section{The school teaching management establish communication platform}

\section{1 school teaching management the significance of communication platform established}

In the school teaching implementation process, schools, teachers and students of communication between appears especially important, the school teaching management school teaching management of participants especially main schools need to get from teachers and students with enough info to your own teaching management, the problems of the rules and regulations for evaluation and test, guarantees the school teaching implementation in the smooth and efficient. But to achieve such effect, teaching management and teachers in schools in the process of implementing, school as the center, the established parties will communicate communication platform for schools, teachers and students and provide a relatively perfect communication between the communication channel is very necessary. This school teaching management interface for the solution of the problem, for improving the school teaching management work will have a very important role.

\section{2 school teaching management methods to set up communication platform of}

Generally speaking, information communication way basically has two kinds. One is the official communication. Another is the informal exchanges. Formal communication mechanism in authority on understandable. Because of the seriousness of the school teaching and scientific, therefore, schools must insist on formal exchanges on communication mechanism to ensure the successful developing of school teaching management. And meanwhile, also must see, the official communication mechanism in the form of information transmission and efficiency exist certain problems, accumulated to affect the school teaching management in the implementation of the validity of information transmission, forming of school, and information interface smooth implementation of teaching activity brings certain obstacles. So, consider using informal exchange combined. So, on the one hand, can avoid the message transfer process, improve the tear and distortion of information transmission quality, on the other hand, still can make choice for the communication mechanism of teaching management activities of the teachers and students to and convenient to accept that.

From informal communication mechanism and the characteristics of the form can see, informal communication in information transfer aspects existing in formal communication can compensate for the exchange theme narrow, exchange content restrictions, information to deliver a slower shortcomings. In the process of teaching management, schools should include recreational activities, by establishing the informal flow of information technology network communication, informal communication mechanism, strengthen the school teaching management department, teachers and students, in order to reduce the contact between the gulf between each other with obstacles, improve the efficiency of information use, guarantees the school teaching and teaching management work smoothly. 
The school is training talents of place, its teaching level and teaching quality will directly affect the teaching effect. And to achieve a higher level of teaching, a high level of teaching management is essential, and is the main way of teaching quality improvement. This paper effort, the hope can to enhance our country's school teaching management level, improve the quality of teaching in schools, have a certain significance.

\section{References:}

[1]Yun Peng. Ordinary schools school-department teaching management practice and reflection.[J] Century Bridge, 2006, (12).

[2] Qinqing He. Brief analysis of Chinese colleges and universities teaching quality information monitoring system.Fujian Computer, 2008, (06).

[3]Ping Cai. Strengthening school school-department teaching management ideas and countermeasures, 2005 (26).

[4]Hongru Ma.Higher school interior teaching quality monitoring system of research and practice $\mathrm{f}$ [J]Anyang engineering college journal, 2007, (02).

[5]YuPing Liu; GuiWei Wang. Teaching secretary in the role of college teaching management. 